\title{
PECULIARITIES OF FLOW AND HEAT TRANSFER IN THE BASE REGION OF GENERIC MODEL OF MARTIAN DESCENT VEHICLE
}

\author{
V. Ya. Borovoy, I. V. Egorov, D. V. Ivanov, \\ and A.S. Skuratov
}

Central Aerohydrodynamic Institute (TsAGI)

Zhukovsky Str. 1, Zhukovsky, Moscow Region 140180, Russia

\begin{abstract}
Some results concerning experimental and numerical investigations of Generic model of Martian descent vehicle (TC3 configuration) are presented. These investigations include determination of heat flux and pressure on the all model surfaces at different angles of attack. Experiments were carried out in TsAGI's wind tunnels UT-1 in air and in IT-2 in carbon dioxide. With the help of total pressure measurements, flow in the model base region has been diagnosed at laminar and turbulent cases. The study is focused on heating of the base surface.
\end{abstract}

\section{INTRODUCTION}

Heating of base surface is of great interest despite the level of heat flux in this region is low. Indeed, reattachment of separated flow on the payload container can result in its damage. Even at absence of reattachment on the vehicle surface, accurate information on maximum base heat flux would be very helpful for estimating necessary heat protection of the base surface. The problem is very important taking into account weight problem for planetary missions.

Numerical and experimental investigations of overflow and heating of planetary probes [1-7] have been intensified. Significant enhancement of heat exchange in the base region is reviled at laminar-turbulent transition of the shear layer. In this case, the calculated heat flux distribution differs significantly from the data, especially in the reattachment zone.

At the experiments in wind tunnels, tail stings are usually used. At that heat flux, measurements are impossible at symmetry point of the base surface where the heat flux is maximal at symmetrical flow. Moreover, presence of the tail sting can modify the base flow due to closure of the separation flow on the hard

This is an Open Access article distributed under the terms of the Creative Commons Attribution-Noncommercial License 3.0, which permits unrestricted use, distribution, and reproduction in any noncommercial medium, provided the original work is properly cited. 
surface instead in the free flow. In the present work, the models are installed in the wind tunnel by the help of side sting. Thus, heat flux measurements are possible over the model back surface including the rear stagnation point zone. Of cause, sting influence is not eliminated fully but according to the data, this influence is small.

For the design of entry vehicle, there is necessary to perform numerical simulations to evaluate convective and radiative heating on the whole surface of the space vehicle at different points of entering trajectories. Prior to such a work, the codes have to be validated with respect to experimental data. Thus, tunnel test rebuilding is part of the code assessment. Within the frame work of this proposal, it was suggested to construct an experimental database in UT-1 and IT-2 TsAGI wind tunnels in air and carbon dioxide. Further extension of the work will concern other facilities in Europe. The TC3 CNES model manufactured and equipped at TsAGI is used to perform this study. The paper presents the results of experimental and numerical investigations of laminar, transitional, and turbulent flows around model of Martian vehicles.

\section{EXPERIMENTAL TECHNIQUE}

The experiments are performed in two short duration wind tunnels TsAGI: in hot-shot wind tunnel IT-2 and shock wind tunnel UT-1. The flow characteristics are presented in Table 1.

In IT-2, high pressure and temperature are produced by electrical discharge in a restricted volume, flow duration is approximately $0.1 \mathrm{~s}$. The tunnel UT-1 worked as a Ludwieg-type tunnel, stationary flow duration is $0.04 \mathrm{~s}$.

Two sensor types were used for heat flux measurements. 'Thin wall' sensors were used for measurements on the front surface, 'surface thermocouples' (foil sensors) were used on the back surface. The main part of the first sensor presents itself a thermocouple $0.2 \times 0.2 \mathrm{~mm}$ and $0.03 \mathrm{~mm}$ thick welded to the stainless still band 0.2-millimeter thick. The foil sensors are shaped as a tape of 0.2-millimeter width and 0.03-0.04-millimeter thick manufactured from thermocouple and glued into heat insulating material. All sensors have been calibrated in the impulse graduating facility ITGU.

Table 1 Flow characteristics

\begin{tabular}{cccccc}
\hline Wind tunnel & Gas & $\mathrm{M}_{\infty}$ & $\mathrm{Re}_{\infty}, 10^{-6} 1 / \mathrm{m}$ & $P_{0}, \mathrm{bar}$ & $T_{0}, \mathrm{~K}$ \\
\hline IT-2 & $\mathrm{N}_{2}$ & $19.1,19.8$ & $0.47,1.33$ & 140,590 & 2300,2000 \\
IT-2 & $\mathrm{CO}_{2}$ & 12 & 0.40 & 350 & 1730 \\
UT-1 & air & 8 & $1.33-6.80$ & $5-26$ & 800 \\
\hline
\end{tabular}




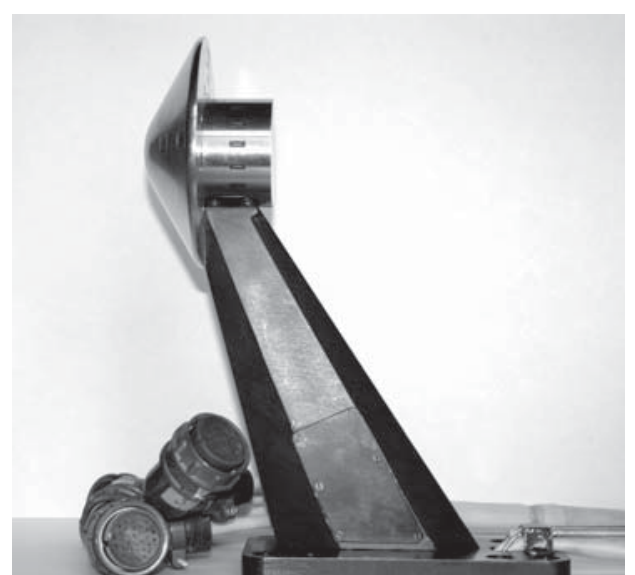

(a)

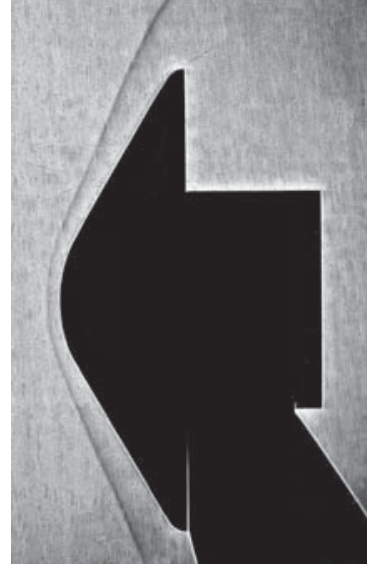

(b)

Figure 1 Mars Sample Return Orbiter (MSRO) model

The measured local heat fluxes were normalized by the measured front stagnation point heat flux at the same flow conditions.

Test case 3 model has diameter $D=120 \mathrm{~mm}$. Sixty one heat flux sensors and seven pressure gages were installed into the model on different model surfaces including butt-end of cylindrical container (Fig. 1a).

\section{NUMERICAL SIMULATION}

Viscous compressible flows are governed by Navier-Stokes. For threedimensional flows, these equations are written in the conservative nondimensional. The fluid is a perfect gas with the specific heat ratio $y=C_{p} / C_{y}=1.4$ and Prandtl number $\operatorname{Pr}=0.7$. The system of equations is closed by state equation $p=\rho T /\left(y \mathrm{M}_{\infty}^{2}\right)$. The viscosity-temperature dependence is approximated by the Sutherland law. The second viscosity is assumed to be zero.

Numerical studies are carried out for hypersonic flow over a Martian model at the freestream Mach and Reynolds numbers corresponding to Table 1 . The boundary conditions on the solid wall are: no-slip condition $(u, v, w)=0$; isothermal $\left(T_{w}=300 \mathrm{~K}\right)$. On the outflow boundary, the unknown variables are extrapolated using a linear approximation. On inflow and upper boundaries, conditions correspond to an undisturbed free stream. Details on the problem formulation and governing equations are given in [8].

The problem is solved numerically using the implicit second-order finitevolume method described in [9]. Three-dimensional Navier-Stokes equations are approximated by a total variation diminishing (TVD) shock-capturing scheme. 


\section{RESULTS AND DISCUSSION}

Distribution of normalized heat flux in the base region for zero angle of attack is presented in Fig. 2. It should be noticed low level of heat transfer at $\mathrm{M}_{\infty}=12$ and 19.8: over the back surface of the heat shield and on the side surface of the cylinder, the heat flux does not exceed $0.3 \%$ of the front stagnation point value. Only at the rear stagnation point, it increases up to $1.4 \%$.

Results of numerical flow simulation are shown in Fig. 3. Inside the global separation zone, secondary circulation flow is visible at the cylinder surface. One more circulation zone formed behind the heat shield. But velocities in these zones are small and their influence on heat exchange is negligible. Boundary of the global separation zone is situated far from the payload container due to its small dimensions. Therefore, heat exchange intensification inherent for reattachment does not take place on the cylinder. Calculation results are compared with the data in Fig. $3 b$. Over the most part of the model, the results correlate with the data. But on the cylinder but-end, the calculated heat flux exceeds the measured value almost 4 times. It points out on the challenges to correct simulation of flows with big separation zones.

For length measurement of near wake, $T$-shaped gage was manufactured (Fig. $4 a$ ). Readings of both sensors are shown in Fig. $4 b$ vs. distance from the cylinder butt-end. At point $X_{0}=103 \mathrm{~mm}$, readings of both sensors coincide. This point is the end of the separation zone (near wake). It means that the related length of the separation zone from the cylinder is $X_{0} / R \approx 1.72$. Corresponding length from the model shoulder where the flow separates is $X_{0}^{\prime} / R \approx 2.3$. The calculated value for the same conditions is bigger: $X_{0}^{\prime} / R \approx 2.72$. This dis-

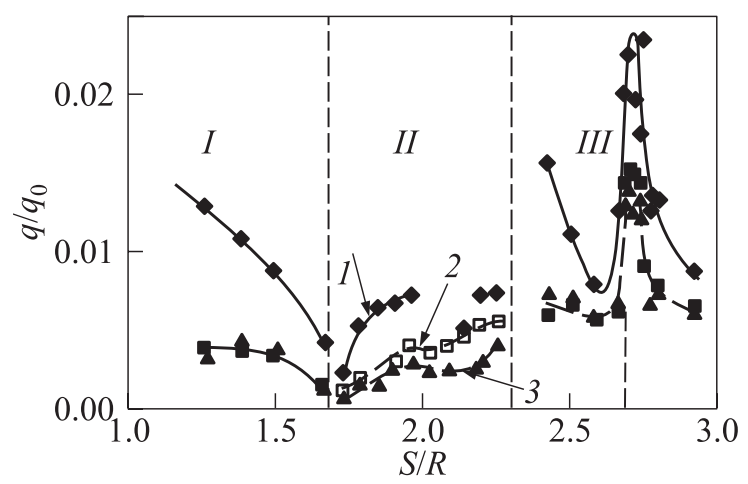

Figure 2 Heat flux distribution over the base surface of the model MSRO: 1 $\mathrm{M}_{\infty}=8, \operatorname{Re}_{\infty, D}=2.57 \cdot 10^{5}$, air $; 2-\mathrm{M}_{\infty}=12, \mathrm{Re}_{\infty, D}=1.6 \cdot 10^{6}, \mathrm{CO}_{2} ;$ and $3-$ $\mathrm{M}_{\infty}=19.8, \operatorname{Re}_{\infty, D}=2 \cdot 10^{5}, \mathrm{~N}_{2}$. Surface regions: $I$ - back surface of the heat shield; $I I$ - cylindrical surface; and $I I I$ - back flat surface of the cylinder 


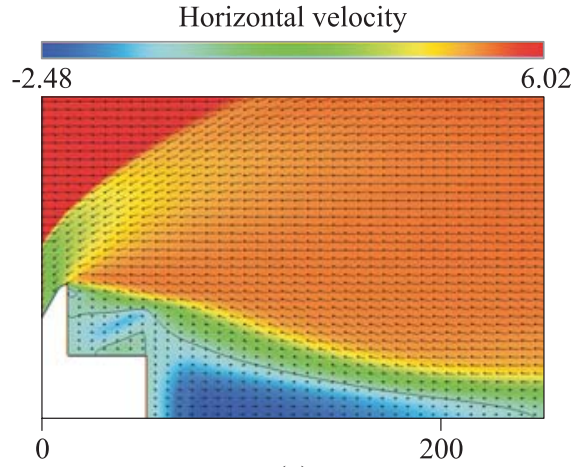

(a)

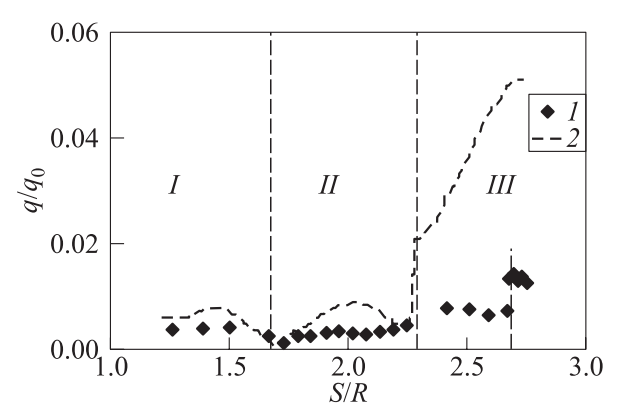

(b)

Figure 3 Model MSRO, $\mathrm{M}_{\infty}=19.8, \operatorname{Re}_{\infty, D}=1.6 \cdot 10^{5}$, nitrogen: ( $a$ ) field of the horizontal velocity component with the line $U=0$, calculations; and (b) heat flux distribution: 1 - experiment and 2 - calculation. (Refer Borovoy et al., p.399.)

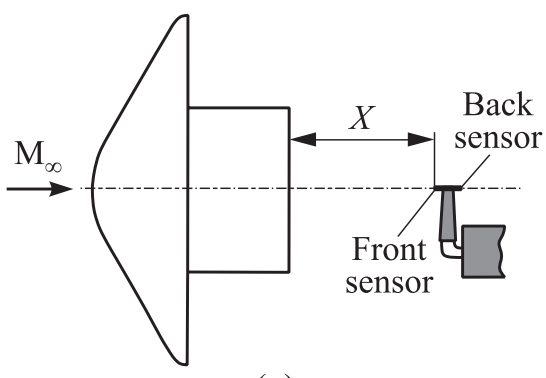

(a)

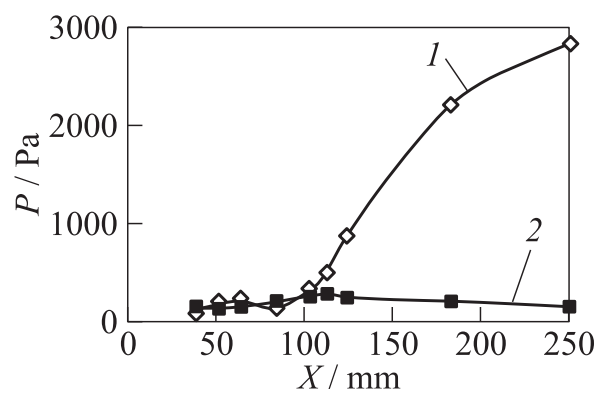

(b)

Figure 4 Stagnation pressure distribution along the axis behind the model MSRO at $\mathrm{M}_{\infty}=8, \operatorname{Re}_{\infty, D}=2.57 \cdot 10^{5}: 1$ - front sensor, 2 - back sensor

crepancy, as well as discrepancy in the heat flux, can be attributed to the error in flow calculation at the free stagnation point of the near wake.

The length of separation zone was estimated in the frame of theory ChapmanKorst $[10,11]$, too. The following results were obtained: for adiabatic flow $\left(T_{w} / T_{0}=1\right) X_{0}^{\prime} / R=2.14$ and for nonadiabatic flow $\left(T_{w} / T_{0}=0.36\right) X_{0}^{\prime} / R$ $=1.61$.

Reattachment point coordinate vs. angle of attack is shown in Fig. 5. When the angle of attack increases, the reattachment point is displaced to the model butt-end, i. e., the length of near wake is reduced.

Relative heat flux distributions along the base model generatrix at three angles of attack at $\mathrm{M}_{\infty}=8$ and laminar base flow are shown in Fig. 6. The different model surfaces are marked in the plot. On the base heatshield surface, 


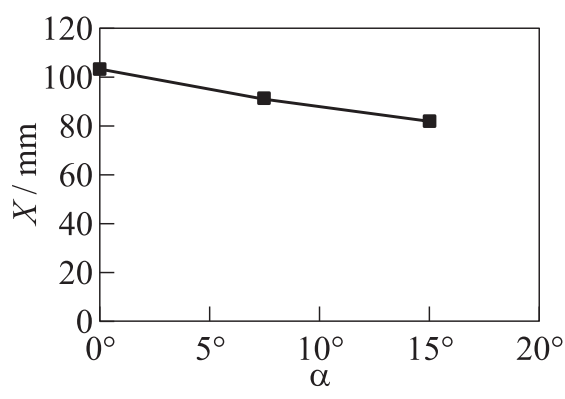

Figure 5 Reattachment point coordinate vs. angle of attack heat flux decreases at approaching to the cylinder. Contrary, on the cylinder generatrix, heat flux increases from heatshield to cylinder butt-end. Maximal heat flux takes place on the cylinder butt-end. Maximal heat flux point is displaced from butt-end center at nonzero angles of attack. Maximal relative heat flux value takes place at $\alpha=7.5^{\circ}$ (2.8\% of the value at the forward stagnation point). Almost on all the base surfaces heat flux is minimal at $\alpha=15^{\circ}$.

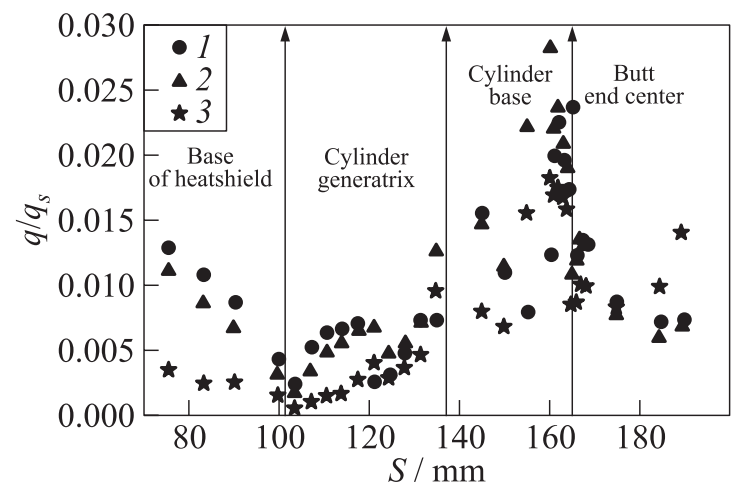

Figure 6 Relative heat flux distribution along the base mode generating at $\mathrm{M}_{\infty}=8$ at three angles of attack $\left(1-\alpha=0^{\circ} ; 2-7.5^{\circ}\right.$; and $\left.3-\alpha=15^{\circ}\right)$ and laminar base flow

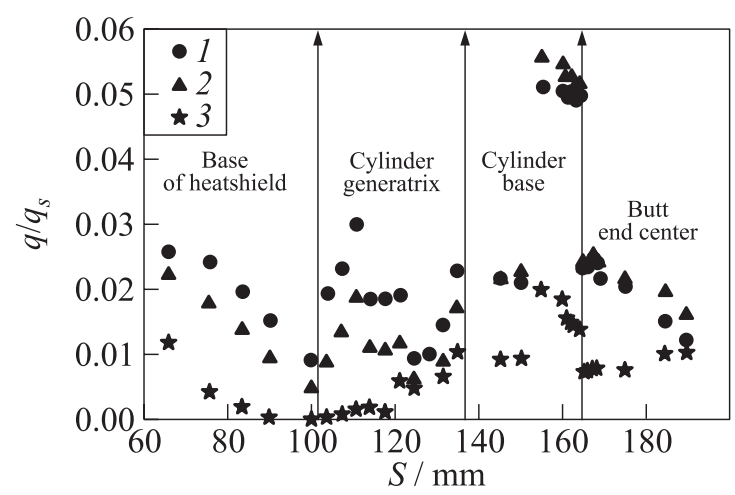

Figure 7 Relative heat flux distribution over the base mode surface at $\mathrm{M}_{\infty}=8$ at three angles of attack $\left(1-\alpha=0^{\circ} ; 2-7.5^{\circ}\right.$; and $\left.3-\alpha=15^{\circ}\right)$ and turbulent flow 


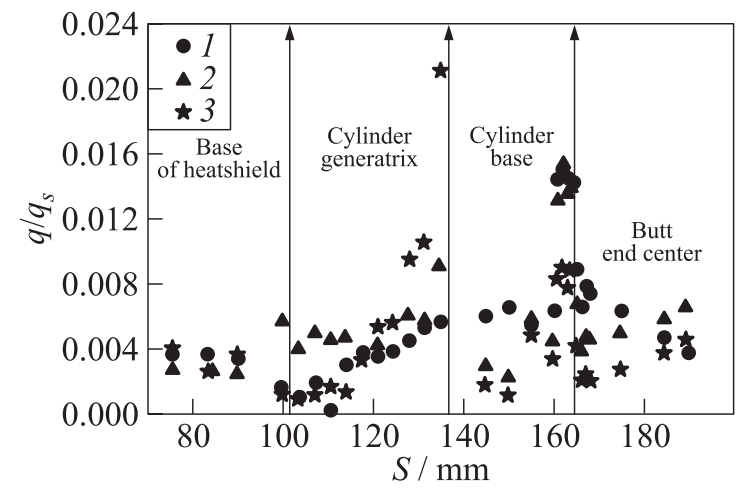

Figure 8 Heat flux distribution over the base mode surface at $M_{\infty}=8$ at three angles of attack $\left(1-\alpha=0^{\circ} ; 2-7.5^{\circ}\right.$; and $\left.3-\alpha=15^{\circ}\right)$ and turbulent flow

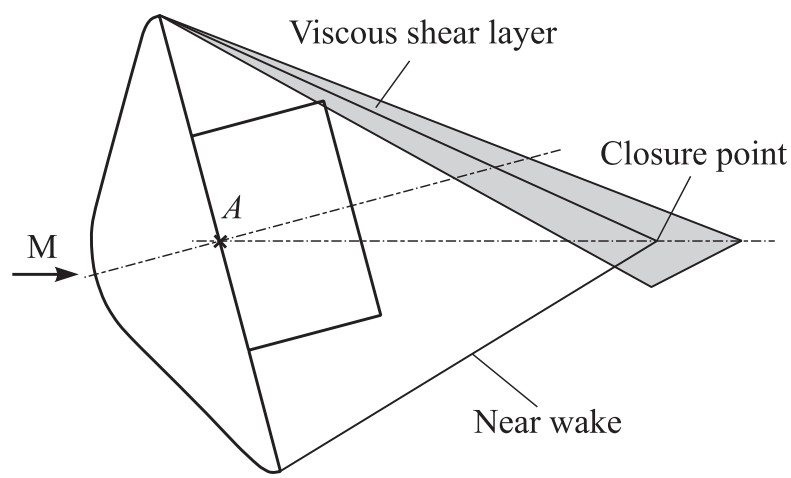

Figure 9 Viscous sheer layer $\left(\alpha=15^{\circ}\right)$

Relative heat flux distribution over base model surface at $\mathrm{M}_{\infty}=8$ and turbulent flow is shown in Fig. 7. On all the base surfaces, heat flux is minimal at $\alpha=15^{\circ}$. Maximal relative heat flux value takes place at $\alpha=7.5^{\circ}\left(q / q_{s}=0.055\right)$ and exceeds corresponding value at laminar flow more than in 2 times.

Heat flux distribution in the base model region in carbon dioxide at $\mathrm{M}_{\infty}$ $=12$ and laminar flow is presented in Fig. 8. At $\alpha=15^{\circ}$, viscous shear layer reattaches to the container surface or touches with it (Fig. 9). Relative heat flux at reattachment point is maximal in the whole of the base region and reaches to $2.1 \%$, and exceeds heat flux on the opposite cylinder end in 15 times. This effect did not take place at $\mathrm{M}_{\infty}=8$. 


\section{ACKNOWLEDGMENTS}

The work was performed under financial support of INTAS (Project \# 03-515204) and Russian Foundation for Basic Research (Project \# 08-08-00565).

\section{REFERENCES}

1. Hollis, B. R., and J. N. Perkins. 1995. Hypervelocity measurements in wake of Mars mission entry vehicle. AIAA Paper No. 95-2314. 12 p.

2. Hollis, B. R., and J. N. Perkins. 1996. Hypervelocity heat-transfer measurements in an expansion tube. AIAA Paper No.96-2240. 12 p.

3. Holden, M., J. Harvey, I. Boyd, J. George, and T. Horvath. 1997. Experimental and computational studies of the flow over a sting mounted planetary probe configuration. AIAA Paper No.97-0768. 22 p.

4. Horvath, T., and K. Hannemann. 1997. Blunt body near-wake flow field at Mach 10. AIAA Paper No. 97-0986. 23 p.

5. Hollis, B. R., and J. N. Perkins. 1997. Transition effects on heating in the wake of a blunt body. AIAA Paper No.97-2569. 16 p.

6. Wright, M., M. Lomis, and P. Papadopouls. 2001. Aerothermal analysis of the Project Fire II afterbody flow. AIAA Paper No. 2001-3065. 15 p.

7. Horvath, T. J., N. C. Heiner, D. M. Olgium, F. M. Cheatwood, and P. A. Gnoffo. 2001. Afterbody heating characteristics of a proposed Mars Sample Return Orbiter. AIAA Paper No. 2001-3068. 16 p.

8. Egorov, I. V., V. G. Sudakov, and A. V. Fedorov. 2006. Direct numerical simulation of disturbances generated by periodic suction-blowing in a hypersonic boundary layer. Theor. Comput. Fluid Dynamics 20(1):41-54.

9. Egorov, I. V., A. V. Novikov, and A.V. Fedorov. 2006. Numerical modeling of the separated flow in a rounded compression corner. Fluid Dynamics 41(4):521-30.

10. Korst, H., and R. Page, and M. Childs. 1956. A theory for base pressures in transonic and supersonic flow. J. Appl. Mech. 23(4):593-600.

11. Chapman, D., D. Kuehn, and H. Larson. 1958. Investigation of separated flows in supersonic and subsonic streams with emphasis on the effect of transition. NACA Report \# 1356. 40 p. 